\title{
Giving in the Face of Risk
}

Citation for published version (APA):

Cettolin, E., Riedl, A., \& Tran, T. G. (2016). Giving in the Face of Risk. Maastricht University, Graduate School of Business and Economics. GSBE Research Memoranda No. 035 https://doi.org/10.26481/umagsb.2016035

Document status and date:

Published: 01/01/2016

DOI:

10.26481/umagsb.2016035

Document Version:

Publisher's PDF, also known as Version of record

\section{Please check the document version of this publication:}

- A submitted manuscript is the version of the article upon submission and before peer-review. There can be important differences between the submitted version and the official published version of record.

People interested in the research are advised to contact the author for the final version of the publication, or visit the DOI to the publisher's website.

- The final author version and the galley proof are versions of the publication after peer review.

- The final published version features the final layout of the paper including the volume, issue and page numbers.

Link to publication

\footnotetext{
General rights rights.

- You may freely distribute the URL identifying the publication in the public portal. please follow below link for the End User Agreement:

www.umlib.nl/taverne-license

Take down policy

If you believe that this document breaches copyright please contact us at:

repository@maastrichtuniversity.nl

providing details and we will investigate your claim.
}

Copyright and moral rights for the publications made accessible in the public portal are retained by the authors and/or other copyright owners and it is a condition of accessing publications that users recognise and abide by the legal requirements associated with these

- Users may download and print one copy of any publication from the public portal for the purpose of private study or research.

- You may not further distribute the material or use it for any profit-making activity or commercial gain

If the publication is distributed under the terms of Article $25 \mathrm{fa}$ of the Dutch Copyright Act, indicated by the "Taverne" license above, 


\section{Maastricht University}

Elena Cettolin, Arno Riedl, Giang Tran

Giving in the Face of Risk

RM/16/035

\section{GSBE}

Maastricht University School of Business and Economics

Graduate School of Business and Economics

P.O Box 616

NL- 6200 MD Maastricht

The Netherlands 


\title{
Giving in the Face of Risk*
}

\author{
Elena Cettolin \\ Arno Riedl \\ Giang Tran
}

November 3, 2016

\begin{abstract}
The decision how to share resources with others often needs to be taken under uncertainty on its allocational consequences. Although risk preferences are likely important, existing research is silent about how social and risk preferences interact in such situations. In this paper we provide experimental evidence on this question. In a first experiment givers are not exposed to risk while beneficiaries' final earnings may be larger or smaller than the allocation itself, depending on the realized state of the world. In a second experiment, risk affects the earnings of givers but not of beneficiaries. We find that individuals' risk preferences are predictive for giving in both experiments. Increased risk exposure of beneficiaries tends to decrease giving whereas increased risk exposure of givers has no effect. Giving under risk is strongly correlated with giving in the absence of risk. We find limited support for existing models of ex-post and ex-ante fairness. Our results point to the importance of incorporating risk preferences in models of social preferences.
\end{abstract}

Keywords: fairness, uncertainty, risk, social preferences, risk preferences, experiment

JEL Classification: C91, D03, D64, D81

\footnotetext{
*Elena Cettolin: Department of Economics, Tilburg School of Economics and Management, Tilburg University, P.O.Box 90153, 5000 LE Tilburg, the Netherlands, e.cettolin@uvt.nl; Arno Riedl (corresponding author): CESifo, IZA, Netspar, Department of Economics (AE1), School of Economics and Business, Maastricht University, P.O.Box 616, 6200 MD Maastricht, the Netherlands, a.riedl@maastrichtuniversity.nl; Giang Tran: Department of Economics (AE1), School of Economics and Business, Maastricht University, P.O.Box 616, 6200 MD Maastricht, the Netherlands, giang.tran@maastrichtuniversity.nl. The research documented in this paper was partly financed by the Oesterreichische Nationalbank (project number 11429) and also received financial support from the Netherlands Organisation for Scientific Research (NWO) (project number 400-09-451).
} 


\section{Introduction}

A large empirical literature shows that individuals are willing to sacrifice on their own material interests to the advantage of others, even if those are anonymous. Interestingly, this evidence has almost exclusively been gathered for situations where the decision to give is made under full information about its distributional consequences 1 Arguably, this information condition is not often met in reality. For example, when donating money to charities there is usually no guarantee about how exactly beneficiaries will benefit (e.g., due to environmental and organizational risks or due to uncertainty about the marginal utility to the beneficiary of an extra dollar of donation). Not only potential beneficiaries, but also givers themselves are often exposed to uncertainty regarding the exact consequences of resources kept. Unless these resources are immediately consumed, welfare effects can substantially vary depending on the giver's exposure to health, safety, or financial risks.

The question is whether such irresolvable uncertainty influences giving behavior and if so how and through which channels? Are people more or less generous when the beneficiaries' or their own personal situation is uncertain? What are the determining factors of giving when final outcomes are risky? Intuitively, social preferences as well as individual risk preferences will affect giving in the face of risk. While there is an extensive literature on the role of social preferences under certainty (Camerer 2003, Engel 2011) and a smaller, growing, literature on ex-post and ex-ante perspectives on fairness under risk (e.g., Brock et al. 2013, Cappelen et al. 2013), to date the role of risk preferences remains unstudied. In this paper we present, to the best of our knowledge, first evidence on how own risk preferences and perceived risk preferences of others affect generosity in situtations where risk cannot be resolved. In addition we link giving behavior to ex-ante and ex-post fairness concerns as recently theoretically formulated in Saito (2013).

We present the results of two stylized experiments designed to investigate how exogenous outcome uncertainty on respectively the givers and beneficiaries side affects giving behavior. The experiments are based on the standard dictator game (Forsythe et al. 1994) and vary riskiness in a controlled way. In the first experiment, givers can make a transfer to beneficiaries who are exposed to various forms of risk (we will refer to this experiment as RISK-B). Importantly, the size of the transfer has to be decided before risk is resolved, and the beneficiaries' final earnings can be smaller or larger than the transfer itself, depending on the realized state of the world. In a second experiment we study generosity in mirror-image situations when givers' final outcomes are risky and known only after the allocation decision, while beneficiaries' outcomes are certain (we refer to this experiment as RISK-G).

1 See Engel (2011) for a meta study on dictator games under certainty. The few recent exceptions taking uncertainty into account will be discussed below. 
In both experiments participants are matched in pairs and randomly assigned the role of either giver (G) or beneficiary (B) 2 To increase salience, both $\mathrm{G}$ and B individually work on a real effort task by which they earn money that is deposited in a joint account of the pair. After the task is completed, $\mathrm{G}$ is asked to divide the deposited money between himself and B, in several allocation problems characterized by different degrees of risk. In experiment RISK-B, G always earns exactly what he keeps while the final earnings of B are risky. Specifically, in each allocation problem B's final earnings are either larger or smaller than the allocation itself, but are in expected value equal to it. Conversely, in experiment RISK-G, G's final earnings are risky and in expectation equal to the share he keeps for himself, while B earns exactly what is allocated to her. In order to examine how risk preferences affect givers' allocation decisions, we elicit participants' own attitude to risk as well as their beliefs about the risk attitude of others, in an incentive comaptible way in both experiments.

Our results show that in both experiments risk preferences of givers are predictive for their allocation choices. In RISK-B, givers' risk-aversion is positively correlated with the shares allocated to beneficiaries, indicating that givers, on average, compensate beneficiaries' exposure to risk by taking into account their own attitudes toward risk. In RISK-G, givers' risk-aversion is negatively correlated with their giving behavior, showing that they compensate themselves for their exposure to risk the more, the more risk averse they are. In both experiments givers' own risk attitudes are positively correlated with their beliefs of beneficiaries risk attitudes, but the latter have basically no predictive power. Thus, givers' own risk preferences appear to be important determinants of their generosity under risk.

These effects of individual risk preferences on generosity are robust to controlling for the riskiness of the allocation problem. Riskiness has an independent effect on giving behavior, which differs between experiments. In RISK-B allocations to the beneficiary are significantly negatively correlated with the riskiness of the beneficiary's earnings, especially when risk is large. In contrast, in RIsK-G, no correlation between giving and the riskiness of the giver's earnings is found.

Extensions of popular models of other-regarding preferences (e.g, Fehr and Schmidt 1999, Bolton and Ockenfels 2000) have been developed in order to analyze ex-ante and ex-post motives of fairness when outcomes are risky (see, e.g., Trautmann 2009, Krawczyk 2011, Saito 2013). These models typically assume (piece-wise) linearity in own and others earnings and are therefore silent about the potential effect of risk aversion (or risk seeking) on allocation decisions. These models nevertheless yield predictions also in our experiments. Indeed, using the model of Saito

\footnotetext{
${ }^{2}$ Throughout the paper we refer to beneficiaries as female and givers as male. In the experiment genders were mixed over roles.
} 
(2013), which can be seen as an extension of previous approaches, we find some limited support for its comparative statics predictions. In addition, we corroborate earlier findings showing that, on average, participants' allocations are consistent with a mix of ex-ante and ex-post fairness motives.

This paper contributes to the small but growing experimental literature that investigates decision situations under risk where social preferences may matter. A few papers explored whether people care about ex-ante (procedural) or ex-post (outcome) fairness or both. Bolton et al. (2005) have been the first to experimentally test procedural fairness and find that people do care for fair procedures. Brock et al. (2013) conduct dictator game experiments with risky outcomes to explore whether ex-post or ex-ante fairness considerations are more important. Their results suggest that both motives contribute to explain dictators' allocation behavior, and that behavior in a standard (risk free) dictator game correlates with giving in risky situations.

In Krawczyk and Le Lec (2010) subjects can share chances to win a prize with an anonymous other in lotteries that are either correlated or independent. They find that dictators give away more chances in the latter case and that motives other than simple inequity aversion are at play when individuals share chances. Cappelen et al. (2013) analyze the allocations of both non-involved subjects and dictators in situations where inequalities in output are the result of antecedent choices under risk. They observe that, although many participants favor some redistribution ex-post, the allocation decisions of most dictators and non-involved subjects are exclusively motivated by the consideration of ex-ante opportunities 3

Our study differs in several aspects from those discussed above. Most importantly, to our knowledge, none has directly addressed the role of individual risk preferences on giving behavior when risk cannot be resolved. We elicit participants' risk preferences and beliefs about the preferences of others in a task free from social aspects. In addition, we systematically vary the potential dispersion of both the beneficiary's and the giver's final outcomes in a way that allows us to investigate (i) how giving responds to the riskiness of the situation and (ii) how idenentical risk on the beneficiary's and the dictator's side, respectively, affects giving behavior. Together, these design elements allow us relating giving behavior to an individuals own and believed risk preferences as well as to the riskiness of own and others earnings.

\footnotetext{
${ }^{3}$ More remotely our paper is also related to studies that investigate how non-involved individuals (spectators) allocate money or chances to individuals in need (Rohde and Rohde 2015, Andreoni et al. 2016, Cettolin and Riedl 2016). Rohde and Rohde (2015) find that spectators are averse to ex-ante inequality and individual risk, while they seek ex-post inequality and collective risk. Andreoni et al. (2016) find that uninvolved individuals exhibit time-inconsistency in their social preferences, in the sense that they can hold incompatible ex-ante and ex-post views of fairness. Cettolin and Riedl (2016) find that spectators are highly heterogeneous in what they consider to be a just allocation under risk, but that on average they tend to allocate less to individuals who are more exposed to risk.
} 
The remainder of the paper is organized as follows. In Section 2 the experimental design is described in detail. Results are presented in Section 3 and in Section 4 we relate them to theoretical predictions of ex-ante and ex-post fairness. In Section 5 concluding remarks are drawn. The experiment's instructions are provided in the Appendix.

\section{Experimental design}

Both experiments, RISK-B and RISK-G, are computerized and consist of three parts. In what follows the different parts are described in detail. We start with Part 1, which can be divided into two sub-parts.

Part 1.a: Real effort task. After all participants have taken a seat in the designated computer station, they are informed that the experiment consists of three parts. The instructions for the first part are then distributed and read out aloud by the experimenter. At the beginning of the first part participants are randomly paired. One participant is assigned the role of giver (G) and the other the role of Beneficiary (B) 4 Roles are fixed throughout the experiment and subjects are informed about this.

Thereafter all subjects work on a real effort task, the so called slider task (Gill and Prowse 2012). On the computer screen 32 sliders on horizontal bars are displayed. Each slider can be moved with the mouse for an unlimited number of times and the position of a slider is displayed to the right of the bar with a number between 0 and 100. A slider is correctly positioned when the number 50 appears, that is when the slider is positioned exactly in the middle of the bar. Productivity is measured by the number of sliders positioned at 50 in 6 minutes time. During the task subjects view their own actual productivity and the amount of time remaining.

The slider task is easy to explain and to understand, is identical across repetitions and has no scope for guessing. The task is incentivized by awarding $€ 0.25$ for each correctly positioned slider, so that each subject can earn up to $€ 8$. After the time for the task has expired, $\mathrm{G}$ and $\mathrm{B}$ in the same pair view each others' productivity and the total amount of money generated, which is deposited in a joint account of the pair. We chose this procedure to increase salience (List) 2007, Bardslev 2008). Furthermore, we calibrated the difficulty of the task such that maximum productivity is relatively easy to achieve, which allows us to focus on situations where $\mathrm{G}$ and $\mathrm{B}$ are equally productive and only differ in their risk exposure 5

\footnotetext{
${ }^{4}$ In the experiment subjects are assigned the neutral labels A and B.

${ }^{5}$ Investigating situations where subjects differ in risk exposure and productivity could be an interesting avenue for future research. For interesting studies on fairness concerns and productivity differences in situations without risk, see Cherrv et al. (2002) and Cappelen et al. (2007).
} 
Part 1.b: Allocation problems. In this part of the experiment, $G$ is asked to distribute the amount of money in the group account between himself and B, who is not active in this phase. G makes decisions in several allocation problems and is informed that only one decision will be randomly selected at the end of the experiment to be relevant for payment.

Table 1 shows the characteristics of each allocation problem in the two experiments. We indicate with $X-x_{n}$ the share kept by $\mathrm{G}$ and with $x_{n}$ the share given to $\mathrm{B}$, in allocation problem $n$. Allocation problem 1-Certainty represents a standard risk-free dictator game, where G's and B's final earnings are equal to the allocation made by G. In the other four allocation problems risk is introduced 6

Table 1: Allocation problems in RISK-B and RIsK-G

\begin{tabular}{llllll}
\hline \hline \multirow{2}{*}{ Problem } & \multicolumn{2}{c}{ RISK-B } & & \multicolumn{2}{c}{ RISK-G } \\
\cline { 2 - 3 } 1-Certainty & $X-x_{1}$ & $x_{1}$ & & G's earnings & $x_{1}$ \\
2-Risk & $X-x_{2}$ & $0.5: 1.5 \cdot x_{2}, 0.5 \cdot x_{2}$ & & $0.5: 1.5 \cdot\left(X-x_{2}\right), 0.5 \cdot\left(X-x_{2}\right)$ & $x_{2}$ \\
3-Risk & $X-x_{3}$ & $0.8: 1.25 \cdot x_{3}, 0 \cdot x_{3}$ & & $0.8: 1.25 \cdot\left(X-x_{3}\right), 0 \cdot\left(X-x_{3}\right)$ & $x_{3}$ \\
4-Risk & $X-x_{4}$ & $0.5: 2 \cdot x_{4}, 0 \cdot x_{4}$ & & $0.5: 2 \cdot\left(X-x_{4}\right), 0 \cdot\left(X-x_{4}\right)$ & $x_{4}$ \\
5-Risk & $X-x_{5}$ & $0.2: 5 \cdot x_{5}, 0 \cdot x_{5}$ & & $0.2: 5 \cdot\left(X-x_{5}\right), 0 \cdot\left(X-x_{5}\right)$ & $x_{5}$ \\
\hline
\end{tabular}

Note: B's earnings in RISK-B are characterized by $p: k \cdot x_{n}, \bar{k} \cdot x_{n}$ and G's earnings in Risk-G by $p: k \cdot(X-$ $\left.x_{n}\right), \bar{k} \cdot\left(X-x_{n}\right)$.

In experiment RisK-B, G's final earnings are equal to the share of $X$ that G keeps for himself, while the final earnings of B depend on which of two possible states of the world is realized. In the table each risky situation is characterized by $p, k$, and $\bar{k}$, with $k>1$ and $0 \leq \bar{k}<1$. With known probability $p$ the good state is realized and B's earnings are $k$ times the share allocated to her, while with known probability $1-p$ the bad state is realized and B's earnings are a fraction $\bar{k}$ of her allocated share. Conversely, in RISK-G, G's final earnings are risky, while B's earnings are certain and equal to the share chosen by $\mathrm{G}$.

In both experiments and in every allocation problem, the expected value of a given allocation is equal to the allocation itself. This property ensures that givers' behavior cannot be explained by the desire to achieve greater material efficiency in expectation. To illustrate, consider distribution problem 4-Risk. In experiment Risk-B, with probability $p=0.5$, B's earnings are either $2 * x_{4}$ or zero, and in expectation thus equal to $x_{4}$ and G's earnings are equal to $X-x_{4}$ for sure. Conversely, in experiment RISK-G the earnings of B are certain and equal to $x_{4}$, while $\mathrm{G}$ earns $X-x_{4}$ in expectations $\left(0.5 * 2 *\left(X-x_{4}\right)+0.5 * 0\right)$.

\footnotetext{
${ }^{6}$ We also implemented two allocation problems characterized by ambiguity. We do not discuss them in the main text but present their characteristics and results in Appendix A.2
} 
Importantly, in both experiments, G makes allocation decisions before risk is resolved and with complete knowledge of how risk affects final earnings. The allocation problems are ordered from least risky, 1-Certainty, to most risky, 5-Risk.7 By varying the riskiness of the allocation problems we can study whether, beyond the mere presence of risk, giving is also affected by how extreme the final distribution of outcomes can be.

In the experiment allocation problems appear on the computer screen one at a time and the order of appearance is randomized at the G-B pair level. Subjects are informed that the resolution of risk and the determination of earnings takes place publicly at the end of the experiment, and that they will witness how the chance devices are operated. In case a risky distribution problem is selected for payment, a stack of cards numbered from 1 to 100 is used to resolve risk. For instance, if B faces a 50 percent chance that her allocation is doubled, then this indeed happens if a card with a number smaller than 51 is drawn.

Part 2: Elicitation of own risk preferences. In this part, we implement incentivized individual decision making tasks in order to elicit participants' own risk preferences. Specifically, we elicit participants' certainty equivalents of six two-outcomes lotteries and use these to estimate subjects' risk preferences at the individual level 8 Table 2 gives an overview of the outcomes and probabilities of these lotteries. For each lottery, subjects make choices between the lottery and 20 equally spaced sure amounts, that are decreasing monotonically from the lottery's highest to lowest outcome. Subjects are not allowed to switch back and forth between the sure amount and the lottery, which guarantees a unique switching point 9

For each lottery, certainty equivalents are calculated as the arithmetic mean of the smallest sure amount preferred to the lottery and the next higher sure amount on the list. Following influential experimental literature estimating risk preferences (e.g., Holt and Laury 2002, Andersen et al. 2008, Wakker 2008, Dohmen et al. 2011), we assume a CRRA power utility function for money $U(x)=x^{1-r}$, where $0<r<1$ indicates risk averse, $r=0$ risk neutral and $r<0$ risk seeking preferences. We estimate the risk preference parameter $r$ at the individual level by minimizing the sum of squared distances (Wakker 2008). That is,

$$
\min _{r} \sum_{i=1}^{6}\left(l_{i}(r)-c e_{i}\right)^{2},
$$

\footnotetext{
${ }^{7}$ An allocation problem $n+1$ is defined as being riskier than problem $n$ if for any constant relative risk aversion (CRRA) or constant absolute risk aversion (CARA) utility function for money, the expected utility of a given risky allocation in $n$ is larger than the expected utility of the same allocation in $n+1$.

${ }^{8}$ Subjects engaged also in six ambiguous lotteries, which are not used in estimating risk preferences.

${ }^{9} \mathrm{~A}$ screenshot showing how lotteries are presented to subjects can be found in Appendix C.
} 
Table 2: Lotteries to elicit risk preferences

\begin{tabular}{cccc}
\hline \hline Lottery & $p_{1}$ & $x_{1}$ & $x_{2}$ \\
\hline 1 & 0.20 & 40 & 0 \\
2 & 0.50 & 16 & 0 \\
3 & 0.80 & 10 & 0 \\
4 & 0.50 & 12 & 4 \\
5 & 0.25 & 16 & 4 \\
6 & 0.33 & 12 & 0 \\
\hline
\end{tabular}

Note: $p_{1}$ is the probability of winning $€ x_{1}$.

where $l_{i}(r)$ indicates the theoretically predicted certainty equivalent for lottery $i$ given $r$ and $c e_{i}$ is the elicited certainty equivalent of lottery $i$. To correct for heteroscedasticity lotteries are normalized to uniform length. At the end of the experiment one decision is randomly selected to be relevant for payment and earnings are added to those of the first part.

Part 3: Elicitation of beliefs about others' risk preferences. In order to elicit participants' beliefs about others' risk preferences, we ask them to estimate the choices made by the other group member in four of the six risky lotteries of Part 2.10 Belief elicitation is incentivized using the interval scoring rule 11 That is, participants are asked to estimate the interval that contains the switching point of the other person, also allowing for indicating a unique switching point. If the true switching point of the other person lies inside the indicated interval, the subject earns an amount that is inversely proportional to the length of the indicated interval. If the true switching point lies strictly outside the indicated interval, the subject earns nothing.

We use the midpoints of the elicited intervals to calculate believed certainty equivalents. These are then used to estimate, at the individual level, a measure $\bar{r}$ of beliefs about others' risk preferences, using the same estimation method as described above for estimating own risk preferences.

In this part subjects could earn a maximum of $€ 1$ per lottery. After it is over subjects fill in a post-experiment questionnaire asking questions about their age, gender, study etc. Thereafter their total earnings are determined and they are paid out confidentially in cash.

\footnotetext{
${ }^{10}$ Participants also estimated choices of the other group member in two ambiguous lotteries. These are not used for the estimation of believed risk preferences of others.

${ }^{11}$ The interval scoring rule is less time consuming and cognitively less demanding for subjects than, for example, the quadratic scoring rule. Further, Schlag and van der Weele (2015) show that it allows inferences that are valid under any degree of subjects' risk aversion.
} 
In total 298 students from Maastricht University participated in the computerized experiment which was conducted at the Behavioral and Experimental Economics lab (BEElab) of Maastricht University School of Business and Economics, using the z-Tree software (Fischbacher 2007). 80 percent of the subjects were enrolled in the School of Business and Economics and the remaining 20 percent followed other studies, such as law, medicine and arts. 48 percent of the subjects were male and the average age was 24 years. The experiment lasted approximately 75 minutes, the average earnings per subject were $€ 22$.

\section{Results}

In the real effort task, most subjects were equally and maximally productive, as intended. Specifically, both $\mathrm{G}$ and $\mathrm{B}$ achieved the maximum of $€ 8$ in 66 of 73 pairs in RISK-B and in 71 of 76 pairs in RISK-G. As our focus is the analysis of the effects of risk and risk preferences on giving, in the following we exclude those pairs where at least one person did not earn the maximum of $€ 8$. Consequently, in the analyzed pairs the joint account always contains $€ 16$. Below, we first present the results of experiment Risk-B followed by the results of experiment RISK-G. For both experiments, we begin by providing some descriptive statistics on all allocation problems. Thereafter, we provide regression analyses on the effect of individual risk preferences and varying riskiness.

Experiment Risk-B. Table 3 provides summary statistics on giving in RISK-B 12 We note first that allocations in problem 1-Certainty are in keeping with what is commonly observed in standard dictator games (see Camerer 2003, Engel 2011). Givers transfer on average $€ 3.70$, that is $23 \%$ of the joint account, to the beneficiary, a substantial share of $23 \%$ of givers choose the equal split of $€ 8,32 \%$ allocate nothing to $B$, and only very few (3\%) give more than the equal split.

Comparing giving in the different allocation problems, Table 3 shows that on average it is first slightly increasing but than decreases to a minimum in the most risky problem 5-Risk. The figures in the third column of the table show that the number of givers that choose to split the joint account equally decreases with the riskiness of the problem. The frequency of the selfish choice to give nothing is highest in 1-Certainty but does not differ across risky allocation problems. Finally, 'hyperfair' choices of giving more than the equal split are generally infrequent but appear more often in the risky problems than in 1-Certainty.

To test if risk preferences are predictive for giving we first estimate the risk aversion parameter $r$, as described in Part 2 of Section 2, Consistent with previous experimental results (e.g.,

\footnotetext{
${ }^{12}$ Appendix A.1 provides histograms of the distributions of giving for all allocation problems.
} 
Table 3: Summary statistics of giving in RISK-B

\begin{tabular}{lccccc}
\hline \hline \multicolumn{1}{c}{ Problem } & Mean $\left(x_{n}\right)$ & Std.dev. $\left(x_{n}\right)$ & Equal split & No giving & More than equal \\
\hline 1-Certainty & 3.70 & 3.69 & $23 \%$ & $32 \%$ & $3 \%$ \\
2-Risk & 4.12 & 3.63 & $20 \%$ & $26 \%$ & $5 \%$ \\
3-Risk & 4.25 & 3.77 & $14 \%$ & $26 \%$ & $12 \%$ \\
4-Risk & 3.69 & 3.45 & $11 \%$ & $26 \%$ & $5 \%$ \\
5-Risk & 3.00 & 3.28 & $6 \%$ & $27 \%$ & $8 \%$ \\
\hline
\end{tabular}

Note: $N=66$; 'Mean' in $€$; 'Equal split', 'No giving', and 'More than equal' are frequencies in percent.

Holt and Laury 2002), we find that givers are on average moderately averse to risk (mean $r=$ 0.27 , std.dev. $(r)=0.30)$. We then use these individual level estimates as an explanatory variable in regression analyses with the various measures of giving presented in Table 3 as dependent variables.

Table 4 shows the results. Specifications (1)-(2) report OLS regressions with $€$ allocations to the beneficiary as dependent variable. Specifications (3)-(8) report Probit regressions where the dependent variable takes on value 1 if, respectively, an equal split is offered (Equal split), nothing is given to the beneficiary (Selfish), and more than the equal split is given (Hyperfair). In all Probit specifications the dependent variable takes on value 0 otherwise. In all regressions standard errors are adjusted for clustering on the individual giver.

Specification (1) shows that giving is positively and significantly associated with risk aversion. That is, the more risk averse givers are, the more money they allocate to beneficiaries. An increase in risk aversion of 0.1 points increases giving by approximately 30 euro cents. In specification (2),

Table 4: Regressions RIsk-B

\begin{tabular}{|c|c|c|c|c|c|c|c|c|}
\hline & (1) & $(2)$ & (3) & $(4)$ & $(5)$ & (6) & (7) & (8) \\
\hline & Allocation & Allocation & Equal split & Equal split & Selfish & Selfish & Hyperfair & Hyperfair \\
\hline \multirow[t]{2}{*}{ Risk aversion } & $2.853^{* *}$ & $2.853^{* *}$ & 0.176 & 0.175 & $-0.352^{* *}$ & $-0.352^{* *}$ & 0.103 & 0.102 \\
\hline & $(1.1756)$ & $(1.1774)$ & $(0.1111)$ & $(0.1121)$ & $(0.1550)$ & $(0.1551)$ & $(0.0685)$ & $(0.0686)$ \\
\hline \multirow[t]{2}{*}{ Riskiness } & & $-0.183^{* * *}$ & & $-0.042^{* * *}$ & & -0.009 & & 0.008 \\
\hline & & $(0.0678)$ & & $(0.0108)$ & & $(0.0081)$ & & $(0.0053)$ \\
\hline \multirow[t]{2}{*}{ Constant } & $2.977^{* * *}$ & $3.525^{* * *}$ & & & & & & \\
\hline & $(0.4536)$ & $(0.5459)$ & & & & & & \\
\hline Observations & 330 & 330 & 330 & 330 & 330 & 330 & 330 & 330 \\
\hline Adjusted $R^{2}$ & 0.055 & 0.058 & & & & & & \\
\hline Pseudo $R^{2}$ & & & 0.029 & 0.066 & 0.048 & 0.048 & 0.037 & 0.042 \\
\hline
\end{tabular}


riskiness of the allocation problem is added as a trend variable taking on value 1 for 1-Certainty, 2 for 2-Risk and so on. The regression result shows that the effect of risk preferences on allocations is robust to controlling for the riskiness of the allocation problem 13 In addition, riskiness has an independent effect as increasing riskiness significantly decreases allocations to the beneficiary. Thus, on average, givers become less generous the larger the risk beneficiaries have to bear.

Specifications (3)-(4) show no effect of risk preferences on the likelihood of equal splits but indicate that this likelihood decreases with the riskiness of the allocation problem. In contrast, specifications (5)-(6) show that givers who are less risk averse are more likely to make the selfish choice of keeping everything. This is consistent with the above reported result that giving increases with givers' risk aversion. The risk beneficiaries face appears to be unrelated to selfish choices. Finally, the likelihood of allocations larger than the equal split is neither related to risk preferences nor to the riskiness of the allocation problem as can be seen from specifications (7)-(8).

In experiment RISK-B the risk is on beneficiaries and it is therefore conceivable that givers' allocation decisions are also affected by their beliefs about others' risk preferences. In Part 3 of the experiment we have elicited these beliefs $\bar{r}$ and find that they are on average very similar to givers' own risk preferences (mean $\bar{r}=0.28$, std.dev. $(\bar{r})=0.33$ ). Moreover, the two measures, $r$ and $\bar{r}$, are significantly positively correlated (Pearson correlation $=0.54$, p-value $<0.01$ ).

When regressing allocations to $\mathrm{B}$ on the riskiness of the allocation problem and on believed risk preferences of others instead of own risk preferences (cf. specification (2) above) we find that believed risk preferences are marginally significantly and positively correlated with giving (see Table A.3 in Appendix A.3). The strong correlation between $r$ and $\bar{r}$ makes it difficult to determine whether own risk preferences or beliefs about others' risk preferences or both are predictive for giving. However, when adding also own risk preferences as an explanatory variable to the regression these are marginally significant, whereas beliefs about others risk preferences cease to be significant. This suggests that it is rather own risk preferences than beliefs about others risk preferences that affects givers' generosity.

Experiment Risk-G. In this section we analyze giving decisions in RISK-G, that is in allocation problems where givers themselves are exposed to risk. We proceed in the same way as for experiment RISK-B and start with some descriptive statistics shown in Table 514

\footnotetext{
${ }^{13}$ In Section 4 we conduct regressions where we replace the trend variable with dummy variables for each allocation problem. The results regarding the effect of risk preferences are also robust to this change in regression specification.

${ }^{14}$ Appendix A.1 provides histograms of the distributions of giving for all allocation problems.
} 
Table 5: Summary statistics of giving in RISK-G

\begin{tabular}{lccccc}
\hline \hline \multicolumn{1}{c}{ Problem } & Mean $\left(x_{n}\right)$ & Std.dev. $\left(x_{n}\right)$ & Equal split & No giving & More than equal \\
\hline 1-Certainty & 4.17 & 4.15 & $30 \%$ & $34 \%$ & $6 \%$ \\
2-Risk & 3.89 & 3.54 & $15 \%$ & $31 \%$ & $7 \%$ \\
3-Risk & 3.96 & 3.59 & $14 \%$ & $27 \%$ & $7 \%$ \\
4-Risk & 4.44 & 3.84 & $17 \%$ & $28 \%$ & $10 \%$ \\
5-Risk & 3.99 & 4.06 & $15 \%$ & $37 \%$ & $11 \%$ \\
\hline
\end{tabular}

Note: $N=71$; 'Mean' in $€$; 'Equal split', 'No giving', and 'More than equal' are frequencies in percent.

Allocations in 1-Certainty are similar to those observed in the same problem in experiment RISK-B and in standard dictator games 15 Givers allocate on average $€ 4.17$ to the beneficiary, that is $26 \%$ of the joint account. $30 \%$ of givers choose the equal split, $34 \%$ give nothing to B, and $6 \%$ give more than the equal split of $€ 8$.

The average allocations in Table 5 do not exhibit a clear pattern along the riskiness dimension, suggesting that on average allocations are not related to the riskiness of G's earnings. Interestingly, the frequency of equal splits drops by $50 \%$ when moving from 1-Certainty to 2-Risk but stays more or less constant across the different allocations problems with risk. In contrast, the frequency of selfish choices is largely unaffected by the risk borne by G. On the other hand, hyperfair allocations of more than the equal split appear to be slightly increasing with the riskiness of the allocation problem.

Similar to experiment Risk-B, also in RISK-G givers are moderately risk averse (mean $r=$ 0.14 , std.dev. $(r)=0.37) 16$ To test for the effect of risk preferences we conduct regression analyses with specifications equivalent to those for experiment RISK-B. Table 6] reports the results. Specifications (1)-(2) show that allocations to B are significantly negatively related with risk aversion of the giver. That is, the more risk averse givers are, the less they give to beneficiaries. Thus, givers appear to compensate themselves for their exposure to risk the more, the more risk averse they are. This resonates well with the finding in RISK-B where we observe that the more risk averse givers are, the more they compensate beneficiaries for their risk exposure. In contrast to Risk-B, the riskiness of the allocation problem is not a significant determinant of giving.

The Probit estimates in specifications (3)-(4) show that G's risk aversion is unrelated to the likelihood of splitting resources equally and that it is significantly decreasing with the riskiness

\footnotetext{
${ }^{15}$ There is no statistically significant difference between RISK-G and RISK-B when comparing giving in 1Certainty (Mann-Whitney rank-sum test, $p=0.6243,2$-sided).

${ }^{16}$ Compared to RISK-B, givers in RISK-G are marginally significantly less risk averse (Mann-Whitney rank-sum test, $p=0.0508$, two-sided.)
} 
Table 6: Regressions RISK-G

\begin{tabular}{|c|c|c|c|c|c|c|c|c|}
\hline & (1) & (2) & (3) & (4) & $(5)$ & $(6)$ & (7) & (8) \\
\hline & Allocation & Allocation & Equal split & Equal split & Selfish & Selfish & Hyperfair & Hyperfair \\
\hline \multirow[t]{2}{*}{ Risk aversion } & $-1.672^{* *}$ & $-1.672^{* *}$ & -0.011 & -0.013 & -0.021 & -0.021 & $-0.117^{* *}$ & $-0.118^{* * *}$ \\
\hline & $(0.7280)$ & $(0.7291)$ & $(0.0740)$ & $(0.0733)$ & $(0.0923)$ & $(0.0922)$ & $(0.0454)$ & $(0.0455)$ \\
\hline \multirow[t]{2}{*}{ Riskiness } & & 0.025 & & $-0.027^{* *}$ & & 0.004 & & $0.016^{* *}$ \\
\hline & & $(0.1083)$ & & $(0.0121)$ & & $(0.0123)$ & & $(0.0076)$ \\
\hline \multirow[t]{2}{*}{ Constant } & $4.367^{* * *}$ & $4.293^{* * *}$ & & & & & & \\
\hline & $(0.4043)$ & $(0.5177)$ & & & & & & \\
\hline Observations & 345 & 345 & 345 & 345 & 345 & 345 & 345 & 345 \\
\hline Adjusted $R^{2}$ & 0.023 & 0.021 & & & & & & \\
\hline Pseudo $R^{2}$ & & & 0.000 & 0.011 & 0.000 & 0.000 & 0.063 & 0.075 \\
\hline
\end{tabular}

of the allocation problem. Thus, as in RISK-B, also in RISK-G givers are less inclined to share resources equally when earnings become more risky. Interestingly, selfish choices of giving nothing are related neither to givers' risk aversion nor to the riskiness of the allocation problem (see specifications (5)-(6)). In contrast, specifications (7)-(8) show that the likelihood of making hyperfair offers of more than the equal split are significantly negatively related to givers' risk aversion and significantly positively related to the riskiness of the allocation problem.

Similarly to Risk-B, we find that beliefs about the preferences of others are on average similar to givers' own risk preferences (mean $\bar{r}=0.14$ std.dev. $(\bar{r})=0.42$ ) and that the two measures are positively correlated (Pearson correlation $=0.59$, $\mathrm{p}$-value $<0.01$ ). We have also run regressions with allocations as dependent variable and beliefs about risk preferences of others as (additional) explanatory variable. In these regressions beliefs are never significant, irrespective of whether they are included next to only riskiness or next to riskiness and own risk aversion. The latter remain significantly negative when including believed risk preferences (see Table A.3 in Appendix A.3). Hence, in RISK-G own risk preferences are robust determinants of givers' generosity under risk.

\section{Ex-ante and ex-post fairness}

Recently theoretical models of social preferences where risk is explicitly taken into account have been proposed (see, e.g., Trautmann 2009, Krawczyk 2011, Saito 2013). 17 These models assume (piece-wise) linearity in own and others' earnings and are therefore silent about the effect of risk-

\footnotetext{
${ }^{17}$ See also (Fudenberg and Levine 2012) for a discussion on the problems of extending social preferences models to lotteries.
} 
aversion found in our experiments. However, these models can nevertheless give some insights into behavior as they allow for an ex-ante and an ex-post view of fairness. In this section we discuss to what extend such a model can qualitatively organize our data.

Specifically, we use the model by Saito (2013) to derive theoretical predictions for both experiments and each allocation problem in our experiment 18 The model extends other-regarding preferences à la Fehr and Schmidt (1999) to the case where allocation decisions are made under risk. In particular, it is assumed that in choosing an allocation $\mathbf{x}$ the decision maker may care both about inequality in ex-ante expected payoffs and in ex-post realized outcomes, as described by

$$
V(\mathbf{x})=\delta U\left(E_{p}(\mathbf{x})\right)+(1-\delta) E_{p}(U(\mathbf{x}))
$$

The term $U\left(E_{p}(\mathbf{x})\right)$ captures the utility of expected payoffs and is referred to as ex-ante utility. In contrast, the term $E_{p}(U(\mathbf{x}))$ captures the expected utility of ex-post payoffs and is referred to as ex-post utility. The parameter $\delta \in[0,1]$ measures the relative importance that the decision maker attributes to ex-ante utility. The function $U(\mathbf{x})=x_{i}-x_{j}-\alpha \max \left\{x_{j}-x_{i}, 0\right\}-\beta \max \left\{x_{i}-x_{j}, 0\right\}$ reflects a version of the inequity aversion model of Fehr and Schmidt (1999), where $x_{i}$ is the monetary final payoff of the decision maker $i$ (giver in our experiments), $x_{j}$ is the final payoff of another person $j$ (beneficiary in our experiments) and $\alpha>0(\beta \in[0,1[)$ capture aversion to disadvantageous (advantageous) inequality.

Table 7 summarizes the predictions of the model for the extreme cases of exclusively ex-ante concerns $(\delta=1)$ and exclusively ex-post concerns $(\delta=0)$, assuming sufficiently strong concern for others payoff 19 It follows straightforwardly that for $0<\delta<1$ allocations are predicted to lay in between these two extremes. In case of weak concerns for others, givers are predicted to allocate nothing to beneficiaries.

Comparing these predictions with the average actual allocations reported in Tables 3 and 5 , we see that the latter are positive but strictly smaller than the maximum allocations predicted. Thus, allocations are consistent with givers' having, on average, other-regarding preferences and a mixture of ex-ante and ex-post concerns. This observation is in line with earlier results (e.g., Krawczyk 2010, Brock et al. 2013).

From the model it also follows that, for given levels of other-regarding concerns, allocations should be correlated across allocation problems. Table 8 reports pair-wise Pearson correlation coefficients of allocations across the different allocation problems for both experiments. It shows that allocations are indeed highly and significantly correlated.

\footnotetext{
${ }^{18}$ We do not aim at conducting a calibration of this specific model of inequality aversion but are rather interested in its comparative statics predictions.

${ }^{19}$ A formal derivation of predicted allocations assuming the model of Saito $(2013)$ is provided in Appendix B
} 
Table 7: Theoretical allocations to B for sufficiently strong other-regarding preferences

\begin{tabular}{lccccc}
\hline \hline & \multicolumn{2}{c}{ Risk-B } & & \multicolumn{2}{c}{ Risk-G } \\
\cline { 2 - 3 } \cline { 5 - 6 } Problem & $\delta=1$ & $\delta=0$ & & $\delta=1$ & $\delta=0$ \\
\hline 1-Certainty & 8 & 8 & & 8 & 8 \\
2-Risk & 8 & 6.4 & & 8 & 5.3 \\
3-Risk & 8 & 7.1 & & 8 & 8.9 \\
4-Risk & 8 & 5.3 & & 8 & 0 \\
5-Risk & 8 & 2.7 & & 8 & 0 \\
\hline
\end{tabular}

Note: Rounded values; the exact values can be found in Appendix B

Next we explore if actual allocations, on average, follow the comparative statics predictions along the riskiness of the allocation problems. We run OLS regressions with allocations of givers as dependent variable and dummy variables indicating the riskiness of the allocation problem as independent variable. These dummies are used to check if allocations change across problems in the direction predicted by the model (see Table 7). In all regressions we control for the effect of givers' risk aversion.

Table 8: Correlations of allocations across allocation problems

\begin{tabular}{|c|c|c|c|c|c|}
\hline & \multicolumn{5}{|c|}{ RISK-B } \\
\hline & 1-Certainty & 2-Risk & 3-Risk & 4-Risk & 5-Risk \\
\hline 1-Certainty & 1.00 & & & & \\
\hline 2-Risk & 0.82 & 1.00 & & & \\
\hline 3-Risk & 0.78 & 0.80 & 1.00 & & \\
\hline 4-Risk & 0.80 & 0.82 & 0.65 & 1.00 & \\
\hline \multirow[t]{3}{*}{ 5-Risk } & 0.78 & 0.79 & 0.61 & 0.84 & 1.00 \\
\hline & \multicolumn{5}{|c|}{ RISK-G } \\
\hline & 1-Certainty & 2-Risk & 3-Risk & 4-Risk & 5-Risk \\
\hline 1-Certainty & 1.00 & & & & \\
\hline 2-Risk & 0.59 & 1.00 & & & \\
\hline 3-Risk & 0.53 & 0.73 & 1.00 & & \\
\hline 4-Risk & 0.42 & 0.52 & 0.60 & 1.00 & \\
\hline 5-Risk & 0.57 & 0.51 & 0.70 & 0.47 & 1.00 \\
\hline
\end{tabular}


Table 9 reports the results of these regressions as well as pairwise comparisons of coefficients of the various levels of riskiness (see lower part of the table). We first note that in both regressions the coefficient of givers' risk aversion is significant. Thus, the effect of givers' risk preferences on allocations, reported in the previous section, is robust to this specification of riskiness (cf. Tables 4 and 6).

Along the riskiness dimension, in RISK-B allocations first slightly increase and then decrease. In 5-Risk allocations are significantly smaller than in all other allocation problems, which is in line

Table 9: Regressions for RISK-B and RISK-G with riskiness dummies

\begin{tabular}{|c|c|c|}
\hline & Allocations Risk-B & Allocations Risk-G \\
\hline \multirow[t]{2}{*}{ Constant (1-Certainty) } & $2.923^{* * *}$ & $4.416^{* * *}$ \\
\hline & $(0.4915)$ & $(0.5165)$ \\
\hline \multirow[t]{2}{*}{ 2-Risk } & 0.424 & -0.290 \\
\hline & $(0.2701)$ & $(0.4308)$ \\
\hline \multirow[t]{2}{*}{ 3-Risk } & $0.552^{*}$ & -0.116 \\
\hline & $(0.3048)$ & $(0.4540)$ \\
\hline \multirow[t]{2}{*}{ 4-Risk } & -0.008 & 0.362 \\
\hline & $(0.2825)$ & $(0.5149)$ \\
\hline \multirow[t]{2}{*}{ 5-Risk } & $-0.697^{* *}$ & -0.203 \\
\hline & $(0.2894)$ & $(0.4662)$ \\
\hline \multirow[t]{2}{*}{ Risk aversion } & $2.853^{* *}$ & $-1.672^{* *}$ \\
\hline & $(1.1828)$ & $(0.7323)$ \\
\hline Observations & 330 & 345 \\
\hline Adjusted $R^{2}$ & 0.059 & 0.015 \\
\hline \multicolumn{3}{|c|}{$\begin{array}{l}\text { Pairwise Comparison of effect of riskiness } \\
(p \text {-values of } F \text {-tests })\end{array}$} \\
\hline 2-Risk vs 3-Risk & 0.6632 & 0.5815 \\
\hline 2-Risk vs 4-Risk & 0.1029 & 0.1390 \\
\hline 2-Risk vs 5-Risk & 0.0002 & 0.8519 \\
\hline 3-Risk vs 4-Risk & 0.1431 & 0.2432 \\
\hline 3-Risk vs 5-Risk & 0.0022 & 0.8051 \\
\hline 4-Risk vs 5-Risk & 0.0046 & 0.2461 \\
\hline
\end{tabular}

Note: ${ }^{*} p<0.10,{ }^{* *} p<0.05,{ }^{* * *} p<0.01$; OLS regressions; in parentheses standard errors adjusted for 66 (69) clusters on givers level in RisK-B (RISK-G); in RISK-G two givers are excluded from the analysis because their estimated risk aversion is infinite. 
with the theoretical predictions. However, all other pair-wise comparisons are either insignificant or, in the case of 3-Risk, marginally significant in the wrong direction. In RISK-G allocations are not significantly affected by any of the riskiness conditions. This is in stark contrast to the model where allocations are predicted to strongly respond to riskiness of the allocation problem, especially in 4-Risk and 5-Risk. In sum, the model's comparative statics predictions receive some limited support from the data in RIsK-B but are not supported in Risk-G.

\section{Conclusions}

In this paper we investigated individuals' giving behavior in situations where respectively givers and beneficiaries are exposed to various degrees of risk. We also collected data on individuals' risk preferences and on their beliefs about the risk preferences of others, both in isolation from social preferences. We find that givers' risk preferences are an important determinant of generosity. The more risk averse a giver is, the more he allocates to a beneficiary when earnings risk is on the beneficiary's side and the more he allocates to himself when earnings risk is on his, the giver's, side. Beliefs about the risk preferences of others play basically no role. Thus, givers compensate the side that has to bear the risk, taking their own risk preferences into account.

We also relate behavior in our experiments to a model of ex-ante and ex-post views of fairness and find limited support for it. On average giving behavior is consistent with a mix of ex-ante and ex-post fairness, but comparative statics predictions are only partly met when risk is on beneficiaries side and fail when risk is on givers side.

Existing models of other-regarding preferences do not take into account individual risk preferences of those involved. Our evidence shows however that risk preferences are important in social decision situations and that predictive power of such models would likely be improved when explicitly taking into account attitudes toward risk.

It has been shown that risk preferences relate to observable socio-demographic characteristics (see, e.g., Donkers et al. 2001, Dohmen et al. 2011, Von Gaudecker et al. 2011). Therefore, our results, connecting risk preferences with giving, could be useful for policy makers, institutions and firms who benefit from knowing how pro-social behavior of different social groups responds to risks. In addition, our results may be useful for organizations and individuals who have to make allocation decisions under uncertainty. For instance, for charity organizations or individual researchers who have to raise funds, our evidence suggests that projects with high-risk and highreturns may be less successful in attracting funding than projects with a safer outlook.

Our study also leads to a number of new questions that could be tackled in future research. For instance, our design ruled out ex-ante material efficiency concerns, as givers' earnings were in 
expectation always equal to the amount they kept. However, risk averse givers may perceive that the aggregate expected utility at the pair level increases when money is allocated away from the side bearing the risk. If selfish motives are traded off against these type of efficiency concerns, we may observe that there is on average no effect of riskiness on allocations, as observed in our experiment where givers had to bear the risk.

We find that when beneficiaries are exposed to risk, they are allocated less when the riskiness of their earnings is high. This is consistent with givers being more concerned about ex-post than ex-ante fairness. An alternative interpretation is suggested by the observations of Haisley and Weber (2010), who find that generosity decreases in environments where selfserving interpretations of fairness are available for the decision maker (see also Broberg et al. 2007, Dana et al. 2007). Similarly, in our experiment with risk on the beneficiary, givers may behave less generously in riskier allocation problems by focusing on the beneficiary's high possible outcome and ignoring the low one.

In our experiments we have allowed for risk preferences affecting giving and retained expected utility assumptions. There is however ample evidence that observed behavior under risk is also affected by probability weighting (e.g., Wakker 2010). Future research could try to disentangle social preferences, classical risk attitudes like risk aversion, and probability weighting and explore how it affects giving under risk.

Finally, we see large heterogeneity of behaviors in our experiments in both giving under certainty and giving under risk. When there is certainty, this may be accounted for by assuming heterogeneity purely in social preferences. Under risk, additional aspects enter the picture. For instance, in a previous paper we provide evidence that uninvolved individuals differ substantially in their views on what constitutes a just allocation under risk, even if they share the same view when there is certainty (Cettolin and Riedl 2016). It could be interesting to explore whether the large heterogeneity observed in the experiments reported here is also rooted in diverging views of justice under risk. 


\section{References}

Andersen, S., Harrison, G. W., Lau, M. I., and Rutström, E. E. (2008). Eliciting risk and time preferences. Econometrica, 76(3):583-618.

Andreoni, J., Aydin, D., Barton, B., Bernheim, B. D., and Naecker, J. (2016). When fair isn't fair: Sophisticated time inconsistency in social preferences. Available at SSRN: https://ssrn.com/abstract $=2763318$.

Bardsley, N. (2008). Dictator game giving: altruism or artefact? Experimental Economics, $11(2): 122-133$.

Bolton, G. E., Brandts, J., and Ockenfels, A. (2005). Fair procedures: Evidence from games involving lotteries. The Economic Journal, 115(506):1054-1076.

Bolton, G. E. and Ockenfels, A. (2000). A theory of equity, reciprocity and competition. American Economic Review, 100(1):166-193.

Broberg, T., Ellingsen, T., and Johannesson, M. (2007). Is generosity involuntary? Economics Letters, 94(1):32-37.

Brock, J. M., Lange, A., and Ozbay, E. Y. (2013). Dictating the risk: Experimental evidence on giving in risky environments. American Economic Review, 103(1):415-37.

Camerer, C. F. (2003). Behavioral game theory: Experiments in strategic interaction. Princeton University Press, Princeton, NJ.

Cappelen, A. W., Hole, A. D., Sørensen, E. Ø., and Tungodden, B. (2007). The pluralism of fairness ideals: An experimental approach. American Economic Review, 97(3):818-827.

Cappelen, A. W., Konow, J., Sørensen, E. Ø., and Tungodden, B. (2013). Just luck: An experimental study of risk taking and fairness. American Economic Review, 103(4):1398-1413.

Cettolin, E. and Riedl, A. (2016). Justice under uncertainty. Management Science. Forthcoming.

Cherry, T. L., Frykblom, P., and Shogren, J. F. (2002). Hardnose the dictator. American Economic Review, 92(4):1218-1221.

Croson, R. and Gneezy, U. (2009). Gender differences in preferences. Journal of Economic Literature, 47(2):448-474.

Dana, J., Weber, R. A., and Kuang, J. X. (2007). Exploiting moral wiggle room: Experiments demonstrating an illusory preference for fairness. Economic Theory, 33(1):67-80. 
Dohmen, T., Falk, A., Huffman, D., Sunde, U., Schupp, J., and Wagner, G. G. (2011). Individual risk attitudes: Measurement, determinants, and behavioral consequences. Journal of the European Economic Association, 9(3):522-550.

Donkers, B., Melenberg, B., and Van Soest, A. (2001). Estimating risk attitudes using lotteries: A large sample approach. Journal of Risk and Uncertainty, 22(2):165-195.

Engel, C. (2011). Dictator games: A meta study. Experimental Economics, 14(4):583-610.

Fehr, E. and Schmidt, K. M. (1999). A theory of fairness, competition and co-operation. Quarterly Journal of Economics, 114(3):817-868.

Fischbacher, U. (2007). z-Tree: Zurich toolbox for ready-made economic experiments. Experimental Economics, 10(2):171-178.

Forsythe, R. J., Horowitz, J., Savin, N., and Sefton, M. (1994). Fairness in simple bargaining experiments. Games and Economic Behavior, 6(3):347-369.

Fudenberg, D. and Levine, D. K. (2012). Fairness, risk preferences and independence: Impossibility theorems. Journal of Economic Behavior E Organization, 81(2):606-612.

Gill, D. and Prowse, V. L. (2012). A structural analysis of disappointment aversion in a real effort competition. American Economic Review, 102(1):469-503.

Haisley, E. and Weber, R. (2010). Self-serving interpretations of ambiguity in other-regarding behavior. Games and Economic Behavior, 68(2):614-625.

Holt, C. and Laury, S. (2002). Risk aversion and incentive effects. American Economic Review, 92(5):1644-1655.

Krawczyk, M. (2010). A glimpse through the veil of ignorance: Equality of opportunity and support for redistribution. Journal of Public Economics, 94(1-2):131-141.

Krawczyk, M. and Le Lec, F. (2010). egive me a chance!f an experiment in social decision under risk. Experimental Economics, 13(4):500-511.

Krawczyk, M. W. (2011). A model of procedural and distributive fairness. Theory and Decision, 70(1):111-128.

List, J. (2007). On the interpretation of giving in dictator games. Journal of Political Economy, 115(3):482-493. 
Rohde, I. M. and Rohde, K. I. (2015). Managing social risks - tradeoffs between risks and inequalities. Journal of Risk and Uncertainty, 51(2):103-124.

Saito, K. (2013). Social preferences under risk: equality of opportunity versus equality of outcome. American Economic Review, 103(7):3084-3101.

Schlag, K. H. and van der Weele, J. J. (2015). A method to elicit beliefs as most likely intervals. Judgment and Decision Making, 10(5):456-468.

Trautmann, S. (2009). A tractable model of process fairness under risk. Journal of Economic Psychology, 30(5):803-813.

Von Gaudecker, H.-M., Van Soest, A., and Wengström, E. (2011). Heterogeneity in risky choice behavior in a broad population. American Economic Review, 101(2):664-694.

Wakker, P. (2008). Explaining the characteristics of the power (CRRA) utility family. Health Economics, 17(12):1329-1344.

Wakker, P. (2010). Prospect Theory for Risk and Ambiguity. Cambridge: Cambridge University Press. 


\section{A Graphs and additional results}

\section{A.1 Distribution of allocations}

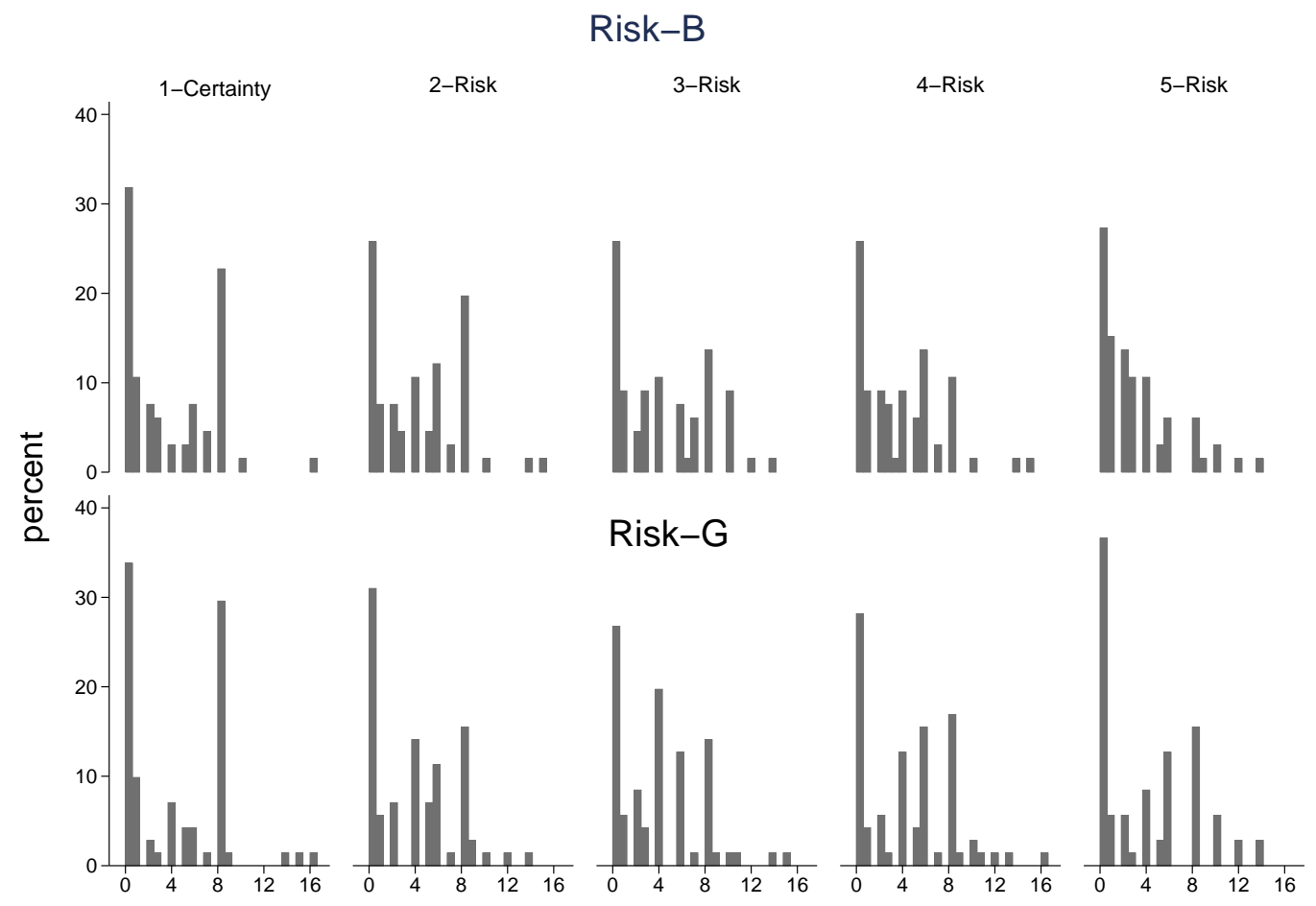

Figure A.1: Giving by allocation problem

\section{A.2 Allocation problems characterized by ambiguity}

The experiment also included two allocation problems characterized by ambiguity. Table A.1 displays the problems' characteristics, where the unknown probability is indicated by $\tilde{p}$. In order to implement ambiguity in the laboratory a stack of 100 cards colored black and red is used. Neither the participants nor the experimenter know the exact color composition of the stack,

Table A.1: Allocation problems with ambiguity in RIsK-B and Risk-G

\begin{tabular}{lllll}
\hline \hline & \multicolumn{2}{c}{ Risk-B } & \multicolumn{2}{c}{ RISK-G } \\
Problem & G's earnings & B's earnings & G's earnings & B's earnings \\
\hline 6-Ambiguity & $X-x_{6}$ & $\tilde{p}: 1.5 \cdot x_{6}, 0.5 \cdot x_{6}$ & $\tilde{p}: 1.5 \cdot\left(X-x_{6}\right), 0.5 \cdot\left(X-x_{6}\right)$ & $x_{6}$ \\
7-Ambiguity & $X-x_{7}$ & $\tilde{p}: 2 \cdot x_{7}, 0 \cdot x_{7}$ & $\tilde{p}: 2 \cdot\left(X-x_{7}\right), 0 \cdot\left(X-x_{7}\right)$ & $x_{7}$ \\
\hline
\end{tabular}

Note: B's earnings in Risk-B are characterized by $\tilde{p}: k \cdot x_{n}, \bar{k} \cdot x_{n}$ and G's earnings in Risk-G by $\tilde{p}$ : $k \cdot\left(X-x_{n}\right), \bar{k} \cdot\left(X-x_{n}\right)$, where $\tilde{p}$ is an unknown probability between 0 and 1 . 
and each participant is free to choose his/her winning color at the beginning of the experiment.

Table A.2 shows descriptive statistics on giving in the presence of ambiguity.

Table A.2: Summary statistics of giving under ambiguity in RISK-B and RISK-G

\begin{tabular}{llccccc}
\hline \hline Experiment & Problem & Mean $\left(x_{n}\right)$ & Std.dev. $\left(x_{n}\right)$ & Equal split & No giving & More than equal \\
\hline \multirow{2}{*}{ Risk-B } & 6-Ambiguity & 3.83 & 3.89 & $12 \%$ & $26 \%$ & $8 \%$ \\
& 7-Ambiguity & 3.82 & 3.48 & $15 \%$ & $24 \%$ & $3 \%$ \\
\hline \multirow{2}{*}{ Risk-G } & 6-Ambiguity & 3.72 & 3.89 & $14 \%$ & $32 \%$ & $10 \%$ \\
& 7-Ambiguity & 4.17 & 3.86 & $20 \%$ & $34 \%$ & $11 \%$ \\
\hline
\end{tabular}

\section{A.3 Beliefs about the beneficiaries risk preferences}

Table A.3 shows how givers' beliefs about the risk preferences of beneficiaries affect their allocation decisions.

Table A.3: Regressions for RIsK-B and RISK-G with beliefs on beneficiaries' risk aversion

\begin{tabular}{|c|c|c|c|c|}
\hline & \multicolumn{2}{|c|}{ Risk-B } & \multicolumn{2}{|c|}{ Risk-G } \\
\hline & Allocation & Allocation & Allocation & Allocation \\
\hline \multirow[t]{2}{*}{ Believed risk aversion } & $2.350^{*}$ & 1.317 & -0.690 & 0.297 \\
\hline & $(1.2158)$ & $(1.3136)$ & $(0.7610)$ & $(0.7650)$ \\
\hline \multirow[t]{2}{*}{ Risk aversion } & & $2.086^{*}$ & & $-1.870^{* *}$ \\
\hline & & $(1.2350)$ & & $(0.7343)$ \\
\hline \multirow[t]{2}{*}{ Riskiness } & $-0.183^{* * *}$ & $-0.183^{* * *}$ & 0.025 & 0.025 \\
\hline & $(0.0678)$ & $(0.0679)$ & $(0.1083)$ & $(0.1084)$ \\
\hline \multirow[t]{2}{*}{ Constant } & $3.647^{* * *}$ & $3.367^{* * *}$ & $4.143^{* * *}$ & $4.282^{* * *}$ \\
\hline & $(0.5226)$ & $(0.5536)$ & $(0.5285)$ & $(0.5263)$ \\
\hline Observations & 330 & 330 & 345 & 345 \\
\hline Adjusted $R^{2}$ & 0.046 & 0.065 & -0.000 & 0.018 \\
\hline
\end{tabular}

\section{A.4 Gender effects}

Several studies have shown that women tend to be more risk averse than man, while gender differences are less clear cut when social preferences are concerned (see Croson and Gneezv 2009, 
for a review). Here we test whether the observed correlation between allocations to B and risk aversion of givers is driven by female participants. The first column in Table A.4 shows that female givers in Risk-B allocate a little more to B than male givers, but this effect is not statistically significant. The second column shows that female participants in RISK-G tend to give a little less to the beneficiaries, but again this effect is not statistically significant. These null-results may be attributed to the fact that in our experiment male and female subjects do not differ much in terms of risk preferences. In experiment RISK-B female givers are not significantly more risk averse than male givers (Mann-Whitney rank-sum test, $p=0.3758,2$-sided) and in experiment Risk-G women are only marginally more risk averse than men (Mann-Whitney ranksum test, $p=0.0525,2$-sided).

Table A.4: Gender effects on giving

\begin{tabular}{|c|c|c|}
\hline & $\begin{array}{l}\text { RISK-B } \\
\text { allocation }\end{array}$ & $\begin{array}{l}\text { RIsK-G } \\
\text { allocation }\end{array}$ \\
\hline Riskiness & $\begin{array}{c}-0.183^{* * *} \\
(0.0678)\end{array}$ & $\begin{array}{c}0.018 \\
(0.1056)\end{array}$ \\
\hline Female & $\begin{array}{c}0.397 \\
(0.7905)\end{array}$ & $\begin{array}{c}-0.155 \\
(0.7380)\end{array}$ \\
\hline Constant & $\begin{array}{l}4.095^{* * *} \\
(0.5948)\end{array}$ & $\begin{array}{l}4.111^{* * *} \\
(0.6146)\end{array}$ \\
\hline Observations & 330 & 355 \\
\hline$R^{2}$ & 0.008 & 0.001 \\
\hline \multicolumn{3}{|c|}{$\begin{array}{l}\text { Note: }{ }^{*} p<0.10,{ }^{* *} p<0.05,{ }^{* * *} p<0.01 ; \\
\text { OLS regressions; in parentheses standard er- } \\
\text { rors adjusted for } 66(69) \text { clusters on givers } \\
\text { level in Risk-B (RISK-G); in RISK-G two } \\
\text { givers are excluded from the analysis because } \\
\text { their estimated risk aversion is infinite. }\end{array}$} \\
\hline
\end{tabular}




\section{B Theoretical Predictions}

Based on the model introduced by Saito (2013), the utility of the giver is defined by the following expression:

$$
V(\mathbf{x})=\delta U\left(E_{p}(\mathbf{x})\right)+(1-\delta) E_{p}(U(\mathbf{x}))
$$

where the function $U$ corresponds to a version of the inequity aversion model of Fehr and Schmidt (1999), i.e. $U(\mathbf{x})=x_{i}-x_{j}-\alpha \max \left\{x_{j}-x_{i}, 0\right\}-\beta \max \left\{x_{i}-x_{j}, 0\right\}$ where $x_{i}$ is the final payoff of the giver, $x_{j}$ is the final payoff of the beneficiary $j$ and $\alpha>0(\beta \in[0,1[)$ capture aversion to disadvantageous (advantageous) inequality. The term $U\left(E_{p}(\mathbf{x})\right)$ captures the utility of expected payoffs, hence it is referred to as ex-ante utility. In contrast, the term $E_{p}(U(\mathbf{x}))$ captures the expected value of final payoffs utility and is referred to as ex-post utility. The term $\delta \in[0,1]$ measures the weight the giver gives to ex-ante utility.

Proposition B.1. Optimal giving $x_{1}^{*}$ in 1-Certainty:

$$
\forall \delta \in[0,1], \quad x_{1}^{*}= \begin{cases}\{0\} & \text { if } \beta \in[0,1 / 2[, \\ {[0,8]} & \text { if } \beta=1 / 2, \\ \{8\} & \text { if } \beta \in] 1 / 2,1[\end{cases}
$$

Proof. In this problem, the ex-ante utility equals the ex-post utility and hence, it also equals the Saito utility:

$$
U\left(E_{p}(\mathbf{x})\right)=E_{p}(U(\mathbf{x}))=V(\mathbf{x})= \begin{cases}16-x_{1}-\beta\left(16-2 x_{1}\right) & \text { if } 0 \leq x_{1} \leq 8 \\ 16-x_{1}-\alpha\left(2 x_{1}-16\right) & \text { if } 8 \leq x_{1} \leq 16\end{cases}
$$

Taking the first derivative of $V(\mathbf{x})$ w.r.t. $x_{1}$, we obtain:

$$
\frac{d V(\mathbf{x})}{d x_{1}}= \begin{cases}-1+2 \beta & \text { if } 0 \leq x_{1} \leq 8 \\ -1-2 \alpha & \text { if } 8 \leq x_{1} \leq 16\end{cases}
$$

Since $\alpha>0$, the optimal allocation to the beneficiary is never larger than 8 and depends on the value of $\beta$ :

$$
x_{1}^{*}= \begin{cases}\{0\} & \text { if } \beta \in[0,1 / 2[ \\ {[0,8]} & \text { if } \beta=1 / 2 \\ \{8\} & \text { if } \beta \in] 1 / 2,1[\end{cases}
$$

These results hold for all $\delta \in[0,1]$.

\section{B.1 Predictions for Risk-B}

We start by analyzing optimal giving in RISK-B when givers only have concerns for ex-ante fairness, i.e. $\delta=1$, and then develop predictions for the cases in which only ex-post fairness matters, i.e. $\delta=0$. 
Corollary B.2. Optimal giving $x_{n}^{*}$ when $\delta=1$ in RISK-B.

$$
x_{n}^{*} \in \begin{cases}\{0\} & \text { if } \beta \in[0,1 / 2[, \\ {[0,8]} & \text { if } \beta=1 / 2, \\ \{8\} & \text { if } \beta \in] 1 / 2,1[,\end{cases}
$$

Proof. If $\delta=1$ the Saito utility equals the ex-ante utility in all allocation problems. This corollary is obtained directly from the proof of problem 1-Certainty.

Proposition B.3. Optimal giving $x_{n}^{*}$ when $\delta=0$ in RISK-B.

\section{2-Risk:}

$$
x_{2}^{*}= \begin{cases}\{0\} & \text { if } \beta \in[0,1 / 2[, \\ {[0,32 / 5]} & \text { if } \beta=1 / 2, \\ \{32 / 5\} & \text { if } \beta \in] 1 / 2,1[\end{cases}
$$

\section{3-Risk:}

$$
x_{3}^{*}= \begin{cases}\{0\} & \text { if } \beta \in[0,1 / 2[, \\ {[0,64 / 9]} & \text { if } \beta=1 / 2, \\ \{64 / 9\} & \text { if } \beta \in] 1 / 2,1[,\end{cases}
$$

4-Risk:

$$
x_{4}^{*}= \begin{cases}\{0\} & \text { if } \beta \in[0,1 / 2[, \\ {[0,16 / 3]} & \text { if } \beta=1 / 2, \\ \{16 / 3\} & \text { if } \beta \in] 1 / 2,1[\end{cases}
$$

\section{5-Risk:}

$$
x_{5}^{*}= \begin{cases}\{0\} & \text { if } \beta \in[0,1 / 2[, \\ {[0,8 / 3]} & \text { if } \beta=1 / 2, \\ \{8 / 3\} & \text { if } \beta \in] 1 / 2,1[,\end{cases}
$$

Proof. In RISK-B the giver's outcome is always $16-x_{n}$. The giver and beneficiary thus have the same outcome when either $16-x_{n}=k x_{n}$ (i.e. $x_{n}=\frac{16}{k+1}$ ) or when $16-x_{n}=\bar{k} x_{n}$ (i.e. $\left.x_{n}=\frac{16}{k+1}\right)$. These values represent 'equality' benchmarks, that allow distinguishing the four following cases:

\begin{tabular}{ccc} 
Ranges of $x_{n}$ & $\frac{d V(X)}{d x_{n}}$ & sign of $\frac{d V(X)}{d x_{n}}$ \\
\hline $0 \leq x_{n} \leq \frac{16}{k+1}$ & $-1+2 \beta$ & $\geq 0 \Leftrightarrow \beta \geq 1 / 2$ \\
$\frac{16}{k+1} \leq x_{n} \leq \frac{16}{k+1}$ & $-1-\alpha p(k+1)+\beta(1-p)(\bar{k}+1)$ & $(1)$ \\
$\frac{16}{k+1} \leq x_{n} \leq 16$ & $-1-2 \alpha$ & $<0$ \\
\hline
\end{tabular}

Given the values of $p, k$ and $\bar{k}$ in the four allocation problems with risk, (1) is always negative. As a result, optimal giving never exceeds $\frac{16}{k+1}$. 


\section{B.2 Predictions for Risk-G}

We start by analyzing optimal giving in RISK-G when givers only have concerns for ex ante fairness, i.e. $\delta=1$, and then develop predictions for the cases in which only ex post fairness matters, i.e. $\delta=0$.

Corollary B.4. Giver's optimal allocation $x_{n}^{*}$ When $\delta=1$ in Risk-G.

$$
x_{n}^{*} \in \begin{cases}\{0\} & \text { if } \beta \in[0,1 / 2[, \\ {[0,8]} & \text { if } \beta=1 / 2, \\ \{8\} & \text { if } \beta \in] 1 / 2,1[,\end{cases}
$$

Proof. If $\delta=1$ the Saito utility equals the ex-ante utility in all allocation problems. This corollary is obtained directly from the proof of problem 1-Certainty.

Proposition B.5. Optimal giving $x_{n}^{*}$ when $\delta=0$ in RISK-G.

2-Risk:

$$
x_{2}^{*}= \begin{cases}\{0\} & \text { if } \beta \in[0,1 / 2[, \\ {[0,16 / 3]} & \text { if } \beta=1 / 2, \\ \{16 / 3\} & \text { if } \beta \in] 1 / 2,1[\end{cases}
$$

\section{3-Risk:}

$$
x_{3}^{*}= \begin{cases}\{0\} & \text { if } \beta \in\left[0, \frac{5+\alpha}{9}[,\right. \\ {[0,80 / 9]} & \text { if } \beta=\frac{5+\alpha}{9}, \\ \{80 / 9\} & \text { if } \beta \in] \frac{5+\alpha}{9}, 1[,\end{cases}
$$

4-Risk:

$$
x_{4}^{*}=0 .
$$

\section{5-Risk:}

$$
x_{5}^{*}=0 .
$$

Proof. In RISK-G the giver's outcome is either $k\left(16-x_{n}\right)$ or $\bar{k}\left(16-x_{n}\right)$, depending on the realized state of the world. Thus, the giver and beneficiary have the same outcome when $x_{n}=k\left(16-x_{n}\right)$ (i.e. $\left.x_{n}=\frac{16 k}{k+1}\right)$ or when $x_{n}=\bar{k}\left(16-x_{n}\right)$ (i.e. $\left.x_{n}=\frac{16 \bar{k}}{k+1}\right)$. These values represent 'equality benchmarks', that allow distinguishing the four following cases:

\begin{tabular}{ccc} 
Ranges of $x_{n}$ & $\frac{d V(X)}{d x_{n}}$ & $\operatorname{sign}$ of $\frac{d V(X)}{d x_{n}}$ \\
\hline $0 \leq x_{n} \leq \frac{16 \bar{k}}{k+1}$ & $-1+2 \beta$ & $\geq 0 \Leftrightarrow \beta \geq 1 / 2$ \\
$\frac{16 \bar{k}}{k+1} \leq x_{n} \leq \frac{16 k}{k+1}$ & $-1-\alpha(1-p)(\bar{k}+1)+\beta p(k+1)$ & $(2)$ \\
$\frac{16 k}{k+1} \leq x_{n} \leq 16$ & $-1-2 \alpha$ & $<0$ \\
\hline
\end{tabular}


Note that $(2)<0$ in all problems but 3 -Risk, where positive allocations are predicted when

$$
(2) \geq 0 \Leftrightarrow \beta \geq \frac{5+\alpha}{9}
$$

That is, when aversion to advantageous inequality is high, while aversion to disadvantageous inequality is not very strong. 


\section{Experimental Instructions}

We report the instructions for experiment RISK-G, the instructions for the experiment RISKB only differ in Part 1.

\section{Introduction speech}

In this experiment you can earn money with the decisions you make. Your earnings may also depend on chance events and the decisions of other participants. At the end of the experiment you will be paid out in cash individually and confidentially. In order to ensure the highest level of anonymity and confidentiality, the payment will be carried out by a person that is not involved in this research project. The experimenters cannot link your earnings and decisions to your identity in any way. During the experiment you are not allowed to communicate in any other way than described in the instructions. If you have any questions please raise your hand. An experimenter will then come to you and answer your questions in private. The experiment consists of 3 parts. You will receive the instructions of a part only after the previous part has ended.

\section{Part 1}

In the first part of the experiment you will be randomly matched into groups of two participants, which will be labeled with the letters A and B. The slider task In this part of the experiment every participant is asked to perform a task that involves correctly positioning sliders on a bar. Below you can see the representation of a slider in the initial position a) and in the correct position b), which is always in the middle of the bar. The slider is positioned correctly if the number that shows up to the right of the slider equals 50 .

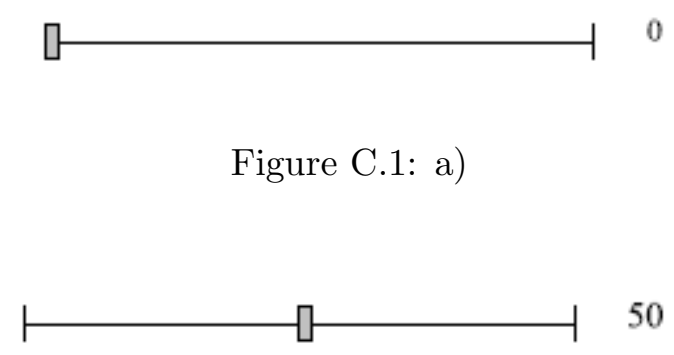

Figure C.2: b)

For each correctly positioned slider 0.25 Euro are credited. There are a total of 32 sliders to be positioned in 6 minutes time, so every participant can credit up to 8 Euro. After the 6 minutes are over, the credit accumulated by A and B, who are in the same group, is deposited in a joint 
group account. Each member of a group (A and B) is then informed about how much she/he and the other member in the group contributed to the joint account.

\section{Determination of earnings}

The task of $\mathrm{A}$ is to divide the amount of money in the joint account between him/herself and B. A is asked to make a division in 7 different decision situations. At the end of the experiment one out of the 7 decisions will be randomly selected to determine the earnings of $\mathrm{A}$ and $\mathrm{B}$. Each decision situation is equally likely to be the one that determines the earnings of $\mathrm{A}$ and $\mathrm{B}$. Therefore, person A should carefully consider each decision and make each decision in isolation. The 7 decision situations differ in the way the amount of money assigned to A and B translates into earnings for $\mathrm{A}$ and $\mathrm{B}$. The table below summarizes the 7 decision situations and shows how the earnings of $\mathrm{A}$ and $\mathrm{B}$ are determined in each decision situation. Notice that during the experiment the 7 decision situations will appear in random order. Please have a look at it.

\begin{tabular}{llr}
\hline Decision & Earnings of A & Earnings of B \\
\hline \hline 1 & allocation to A & allocation to B \\
2 & $20 \%$ chance 5 times allocation to A, $80 \%$ times 0 & allocation to B \\
3 & $50 \%$ chance 2 times allocation to A, $50 \%$ times 0 & allocation to B \\
4 & $80 \%$ chance 1.25 times allocation to A, 20\% times 0 & allocation to B \\
5 & $50 \%$ chance 1.5 times allocation to A, $50 \%$ times 0.5 times allocation to A & allocation to B \\
6 & unknown chance 2 times allocation to A, unknown chance 0 & allocation to B \\
7 & unknown chance 1.5 times allocation to A, unknown chance 0.5 times allocation to A & allocation to B \\
\hline
\end{tabular}

We will now explain each decision situation in detail. If, at the end of the experiment, decision situation 1 is selected to matter for payment then the earnings of $\mathrm{A}$ are equal to the amount $\mathrm{A}$ allocated to him/herself and the earnings of B are equal to the allocation to B.

If, at the end of the experiment, decision situation 2 is selected to matter for payment the earnings of $\mathrm{A}$ are equal to the allocation to A. The final earnings of B depend on the amount of Euro allocated to $\mathrm{B}$ and on a chance event. The chance event will be the public drawing of a card from a stack of 100 cards numbered from 1 to 100. If a card with a number from 1 to 20 will be drawn then the earnings of $\mathrm{B}$ will be 5 times the money allocated to B (i.e., $500 \%$ of the allocation to B). If a number from 21 to 100 will be drawn then the earnings of B will be 0 Euro. In other words, with $20 \%$ chance the earnings of B will be 5 times the allocation to B and with $80 \%$ chance the earnings of $\mathrm{B}$ will be 0 Euro.

If, at the end of the experiment, decision situation 3 is selected to matter for payment the earnings of $\mathrm{A}$ are equal to the allocation to A. The final earnings of B depend on the amount of Euro allocated to B and on a chance event. The chance event will the public drawing of a card from a 
stack of 100 cards numbered from 1 to 100. If a card with a number from 1 to 50 will be drawn then the earnings of B will be 2 times the allocation to B (i.e. $200 \%$ of the allocation to B). If a number from 51 to 100 will be drawn then the earnings of B will be 0 Euro. In other words, with $50 \%$ chance the earnings of B will be 2 times the allocation to $\mathrm{B}$ and with $50 \%$ chance the earnings of B will be 0 Euro.

If, at the end of the experiment, decision situation 4 is selected to matter for payment the earnings of $\mathrm{A}$ are equal to the allocation to A. The final earnings of B depend on the amount of Euro allocated to B and on a chance event. The chance event will the public drawing of a card from a stack of 100 cards numbered from 1 to 100. If a card with a number from 1 to 80 will be drawn then the earnings of $\mathrm{B}$ will be 1.25 times the allocation to B (i.e. $125 \%$ of the allocation to B). If a number from 81 to 100 will be drawn then the earnings of $\mathrm{B}$ will be 0 Euro. In other words, with $80 \%$ chance the earnings of B will be 1.25 times the allocation to B and with $20 \%$ chance the earnings of $\mathrm{B}$ will be 0 Euro.

If, at the end of the experiment, decision situation 5 is selected to matter for payment the earnings of $\mathrm{A}$ are equal to the allocation to A. The final earnings of B depend on the amount of Euro allocated to B and on a chance event. The chance event will the public drawing of a card from a stack of 100 cards numbered from 1 to 100. If a card with a number from 1 to 50 will be drawn then the earnings of $\mathrm{B}$ will be 1.5 times the allocation to B (i.e. $150 \%$ of the allocation to B). If a number from 51 to 100 will be drawn then the earnings of B will be 0.5 times the allocation to B (i.e. $50 \%$ of the allocation to B). In other words, with $50 \%$ chance the earnings of $\mathrm{B}$ will be 1.5 times the allocation to $\mathrm{B}$ and with $50 \%$ chance the earnings of $\mathrm{B}$ will be 0.5 times the allocation to B.

If, at the end of the experiment, decision situation 6 is selected to matter for payment the earnings of $\mathrm{A}$ are equal to the allocation to A. The final earnings of $\mathrm{B}$ depend on the amount of Euro allocated to B and on a chance event. The experimenters will first randomly select black or red to be the winning color. The chance event will then be the public drawing of a card from a stack of 100 cards which are black or red. The total number of red and black cards sums up to 100, but neither A nor B nor the experimenters know how many red cards and how many black cards are in the stack. If a card with the winning color is drawn the earnings of $\mathrm{B}$ will be 2 times the allocation to B (i.e. $200 \%$ of the allocation to B). If a card with the losing color is drawn then the earnings of $\mathrm{B}$ will be 0 Euro. In other words, with an unknown chance the earnings of $\mathrm{B}$ will be 2 times the allocation to $\mathrm{B}$ and with an unknown chance the earnings of $\mathrm{B}$ will be 0 Euro.

If, at the end of the experiment, decision situation 7 is selected to matter for payment the earnings of $\mathrm{A}$ are equal to the allocation to A. The final earnings of $\mathrm{B}$ depend on the amount of 
Euro allocated to B and on a chance event. The experimenters will first randomly select black or red to be the winning color. The chance event will then be the public drawing of a card from a stack of 100 cards which are black or red. The total number of red and black cards sums up to 100, but neither A nor B nor the experimenters know how many red cards and how many black cards are in the stack. If a card with the winning color is drawn the earnings of B will be 1.5 times the allocation to B (i.e. $150 \%$ of the allocation to B). If a card with the losing color is drawn then the earnings of B will be 0.5 times the allocation to B (i.e. $50 \%$ of the allocation to B). In other words, with an unknown chance the earnings of B will be 1.5 times the allocation to $\mathrm{B}$ and with an unknown chance the earnings of $\mathrm{B}$ will be 0.5 times the allocation to $\mathrm{B}$.

If you have any question please raise your hand and an experimenter will come to answer your question in private. In the following you are asked a few questions that will help us assessing your understanding of the decision situations described above. Please fill in the missing figures. Note, that in these questions we are not interested in the actual numbers you fill in but only if you fill them in correctly. During the experiment you will have the possibility to use a calculator by clicking on the icon in the bottom right corner of the screen. When you are ready please raise your hand and an experimenter will come to you to check your answers. Once you are ready please wait quietly.

Consider decision situation 3 and assume that the total in the joint account is 16 Euro. If A assigns. . . Euro to him/herself and ... Euro to B, then this means that with... \% chance B earns ... Euro and with...\% chance ... Euro. A earns ... Euro.

Consider decision situation 5 and assume that the total in the joint account is 15 Euro. If A assigns ... Euro to him/herself and... Euro to B, then this means that with ... \% chance B earns .... Euro and with...\% chance ... Euro. A earns ... Euro.

Consider decision situation 7 and assume that the total in the joint account is 12 Euro. If A assigns ....Euro to him/herself and ... Euro to B, then this means that with ...\% chance B earns ... Euro and with ...\% chance ... Euro. A earns... Euro.

\section{Part 2}

You are now going to make a series of decisions. These decisions will not influence your earnings from the first part of the experiment, nor will the decisions you made in the first part of the experiment influence the earnings from this part. Furthermore, the decisions you are going to make will only influence your own earnings.

You will be confronted with 12 decision situations. All these decision situations are completely independent of each other. A choice you made in one decision situation does not affect any of the other following decision situations. 
Each decision situation is displayed on a screen. The screen consists of 20 rows. You have to decide for every row whether you prefer option A or option B. Option A is the same for every row in a given decision situation, while option B takes 20 different values, one for each row. Note that within a decision situation you can only switch once from option B to option A: if you switch more than once a warning message will appear on the screen and you will be asked to change your decisions. By clicking on NEXT you will see some examples screens of decision situations.

This is a screen shot of a typical decision situation that you are going to face. You are not asked to make choices now! Please have a careful look. Thereafter click on NEXT to proceed.

\begin{tabular}{|c|c|c|c|}
\hline & 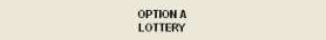 & YOUR C HOCE & 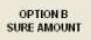 \\
\hline choice 1 & & $A C C \theta$ & 16. \\
\hline choice 2 & & A cra & 15.40 \\
\hline choice 3 & & $A \operatorname{CS} \theta$ & 14.80 \\
\hline choice 4 & & $A C C_{B}$ & 14.20 \\
\hline choice 5 & & A res a & 13.60 \\
\hline choice 6 & & $A \subset C \theta$ & 13.. \\
\hline choice 7 & With $25 \%$ chance you receive 16. - Euro, & $A \subset C B$ & 12.40 \\
\hline choice 8 & Win $15 \%$ cinance you recelve 4.- Euro. & $A C r \theta$ & 11.80 \\
\hline choice 9 & & $A C C \theta$ & 11.20 \\
\hline choice 10 & & $A C r a$ & 10.6 \\
\hline choice 11 & & A $C C_{B}$ & 10. \\
\hline choice 12 & & A CCB & 9.40 \\
\hline choice 13 & & $A C r a$ & 8.80 \\
\hline choice 14 & & Acro & 8.20 \\
\hline choice 15 & & A r s a & 7.60 \\
\hline choice 16 & & $A C C B$ & 7.. \\
\hline choice 17 & & A $r C_{B}$ & 6.40 \\
\hline choice 18 & & $A<C a$ & 5.80 \\
\hline choice 19 & & A $C r a$ & 5.20 \\
\hline choice 20 & & $A \subset C B$ & 4.60 \\
\hline
\end{tabular}

This is another screen shot of a typical decision situation that you are going to face. If you want to review the previous example click on BACK, otherwise click on NEXT to proceed.

\begin{tabular}{|c|c|c|c|}
\hline & 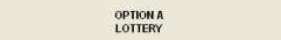 & YOUR CHOFE & 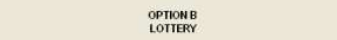 \\
\hline choice 1 & & $A C C_{B}$ & 12. Euro for sure \\
\hline choice 2 & & $\operatorname{Acco} \theta$ & 12. Euro with $95 \%$ chance. 4 - Euro with $5 \%$ chance \\
\hline choice 3 & & $A C r \theta$ & 12. Euro with $90 \%$ chance, 4. Euro with $10 \%$ chance \\
\hline choice 4 & & $\operatorname{Arco}$ & 12. Euro with $85 \%$ chance, 4. Euro with $15 \%$ chance \\
\hline choice 5 & & A $\mathrm{Cr}_{\mathrm{B}}$ & 12. Euro with $80 \%$ chance, 4. Euro with $20 \%$ chance \\
\hline choice 6 & & A Cro & 12. Euro with 75\% chance. 4. Euro with 25\% chance \\
\hline choice 7 & $\begin{array}{l}\text { With unknown chance you either } \\
\text { tecesive } 1 \text {. Euro or 4. Euro }\end{array}$ & $A \subset C a$ & 12. Euro with $70 \%$ chance, 4. Euro with $30 \%$ chance \\
\hline choice 8 & & $\operatorname{Asco} \theta$ & 12. Euro with $65 \%$ chance. 4. Euro with $35 \%$ chance \\
\hline choice 9 & & $A<r a$ & 12. Euro with $60 \%$ chance. 4. Euro with $40 \%$ chance \\
\hline choice 10 & & $A C C B$ & 12. Euro with $55 \%$ chance, 4. Euro with $45 \%$ chance \\
\hline choice 11 & & $\operatorname{A} C r a$ & 12. Euro with $50 \%$ chance. 4- Euro with $50 \%$ chance \\
\hline choice 12 & & $A \subset C B$ & 12. Euro with 45\% chance. 4. Euro with $55 \%$ chance \\
\hline choice 13 & & $A<C B$ & 12. Euro with $40 \%$ chance. 4. Euro with $60 \%$ chance \\
\hline choice 14 & & $A \cos \theta$ & 12. Euro with 35\% chance. 4. Euro with $65 \%$ chance \\
\hline choice 15 & ? & $\operatorname{Acco} \theta$ & 12. Euro with $30 \%$ chance, 4. Euro with $70 \%$ chance \\
\hline choice 16 & & $\operatorname{Arco}$ & 12. Euro with $25 \%$ chance, 4 - Euro with $75 \%$ chance \\
\hline choice 17 & & $\operatorname{A} C r a$ & 12. Euro with $20 \%$ chance, 4 - Euro with $80 \%$ chance \\
\hline choice 18 & & $\operatorname{A} C C \theta$ & 12. Euro with $15 \%$ chance. 4 - Euro with $85 \%$ chance \\
\hline choice 19 & & $A C r \theta$ & 12. Euro with $10 \%$ chance. 4. Euro with $90 \%$ chance \\
\hline choice 20 & & $A<C \theta$ & 12. Euro with $5 \%$ chance, 4. Euro with $95 \%$ chance \\
\hline
\end{tabular}


Determination of earnings At the end of the experiment one of the 12 decision situations will be randomly selected with equal probability. Once the decision situation is selected, one of the 20 rows in this decision situation will be randomly selected with equal probability. The choice you have made in this specific row will determine your earnings.

Consider, for instance, the first screen shot that you have seen. Option A gives you a 25\% chance to earn 16.- Euro and a $75 \%$ chance to earn 4.- Euro. Option B is always a sure amount that ranges from 16.- Euro in the first row, to 4.60 Euro in the 20th row. Suppose that the 12th row is randomly selected. If you would have selected option B, you would receive 9.40 Euro. If, instead, you would have selected option A, the outcome of the lottery determines your earnings. At the end of the experiment the lottery outcome will be publicly determined by randomly drawing a card from a stack of numbered cards.

Consider now the second screen shot that you have seen. Option A gives you an unknown chance to earn 12.- Euro and an unknown chance to earn 4.- Euro. Option B is always a lottery that gives you different chances to earn 12.- Euro or 4.- Euro. Suppose that the 10th row is randomly selected. If you would have selected option B, you would receive 12 .- Euro with $55 \%$ chance and 4.- Euro with $45 \%$ chance. If, instead, you would have selected option A, a stack of red and black cards would be used at the end of the experiment to determine whether you earn 12.- Euro or 4.- Euro. This stack of cards will be the same that has been described in part 1: recall that the exact number of black cards and the exact number of red cards in the stack are unknown to you and to us as well. You would earn 12.- Euro if a card of the winning color is drawn and 4.- Euro otherwise.

Please note that each decision situation has the same likelihood to be the one that is relevant for your earnings. Therefore, you should view each decision independently and consider all your choices carefully. If you like to, you can review the examples screens once more by clicking on BACK. If you have any questions please raise your hand. When you are ready, please press the BEGIN button below.

\section{Part 3}

In the following you are asked to estimate the choices made by the other member in your group in 6 decision situations of the second part of the experiment. After having made these estimates you will answer a questionnaire and then the experiment will be over.

For a certain decision situation you are asked to indicate which is the last row where you believe your matched group member chooses option B before switching to option A. You earn 1 Euro if you correctly indicate the switching point of your matched group member in a certain decision situation. Therefore, you can earn up to 6 Euro in total. If the true switching point of your matched group member is different from the point you indicated you earn nothing. 
If you do not want to indicate a single switching point you can indicate a range of values where you think the switching point of your matched group member lies. If the true switching point lies in this range of values you will earn a positive amount smaller than 1 Euro. The exact amount you earn is calculated according to a formula. The formula captures the idea that earnings are inversely related to the length of the interval you indicate. This means that the larger the interval you indicate the smaller your potential earnings are. This formula also guarantees that your earnings are maximized if you truthfully indicate your estimate. If the true switching point of your counterpart lies outside the interval you indicate you earn nothing. Please click on NEXT to view an example.

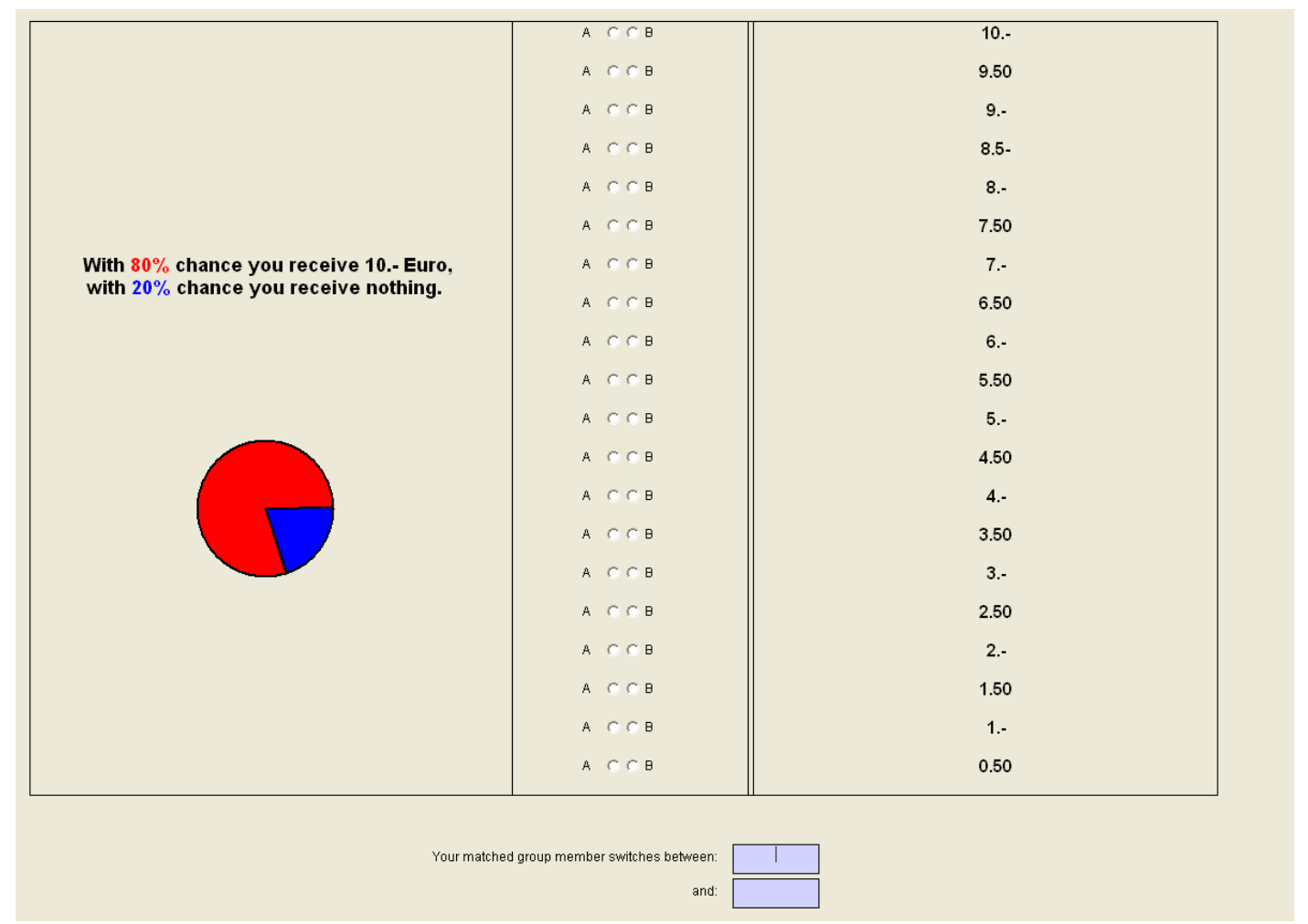

This is a screen shot of a typical screen that you are going to see. Assume, for instance, that you believe that your matched group member chooses option B for the last time when option B is equal to 6.- Euro. In such a case, you would type the number 6 in both boxes at the bottom of the screen.

Assume now that you believe that your matched group member may switch from option B to option A when option B takes any value between 8.- Euro and 4.50 Euro. In such a case, you would type the number 8 in the first box and the number 4.50 in the second box. Notice that you earn nothing if you type in two values that cover all possible switching points, in this case if you type in 10 and 0.50 .

If you have any question please raise your hand. Otherwise click on NEXT to proceed. 


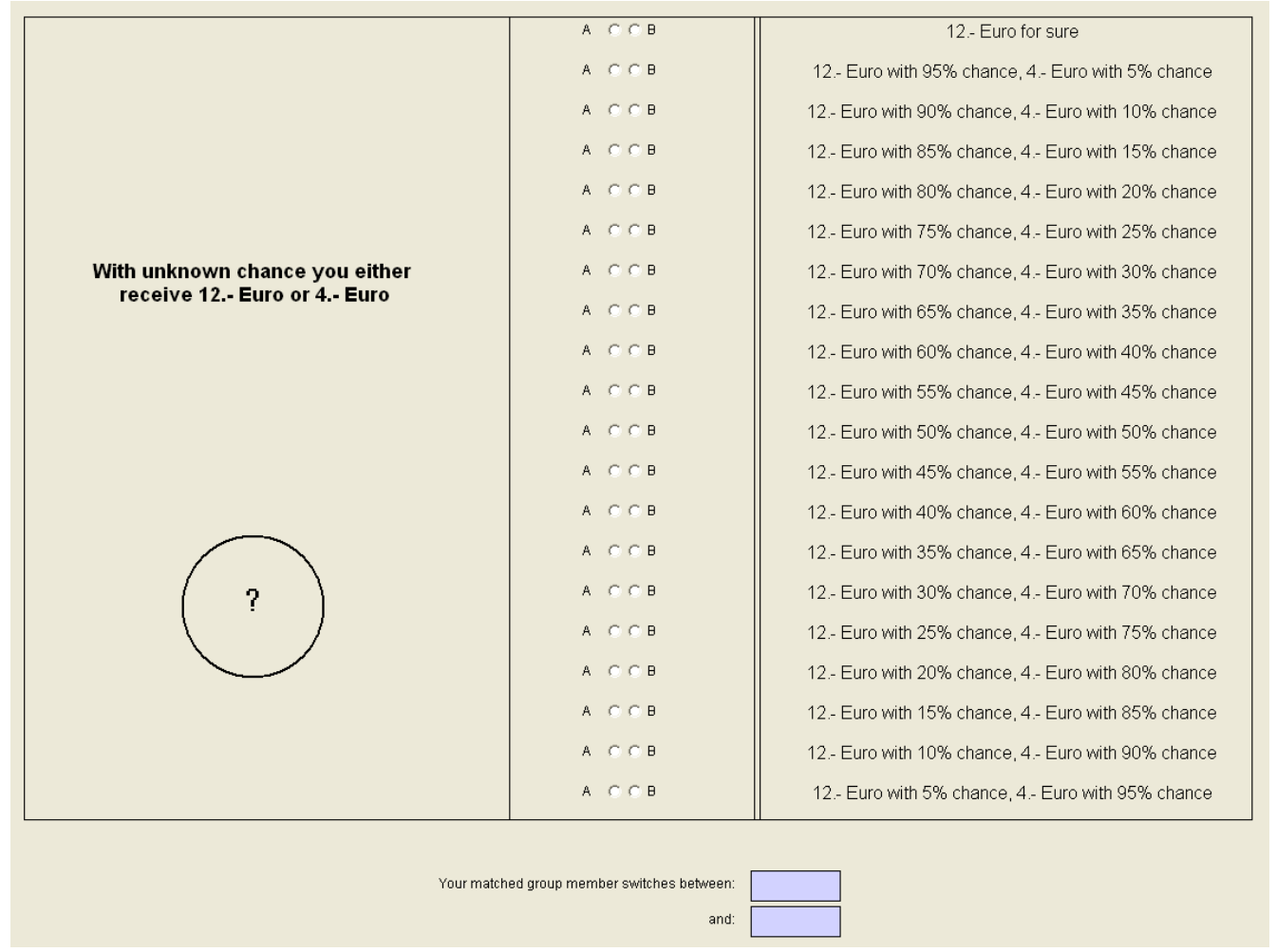

This is another screen shot of a typical screen that you are going to face. Assume, for instance, that you believe that your matched group member chooses option B for the last time when option B gives a chance of $40 \%$ to win 12.- Euro. In such a case, you would type the number 40 in both boxes at the bottom of the screen.

Assume now that you believe that your matched group member switches from option B to option A when the winning chance of option B is between $70 \%$ and $25 \%$. In such a case, you would type the number 70 in the first box and the number 25 in the second box. Notice that you earn nothing if you type in two values that cover all possible switching points, that is if you type in 100 and 5.

If you have any question please raise your hand. If you want to review the previous examples once more click on BACK. Otherwise, click on BEGIN to start the third part of the experiment. 